\title{
Opportunities and risks in e-therapy ${ }^{\dagger}$
}

\section{Digby Tantam}

\begin{abstract}
The world wide web has many advantages for the psychotherapist and for the client, but it poses new challenges too. This article considers both in relation to information, disinformation and information overload; openness and availability of information; and the anomalies of being present, and able to meet other presences, in virtual space but with no physical body and with an identity that may be created for the occasion.
\end{abstract}

This article continues Digby Tantam's consideration in this issue of APT of the implications of electronic media for psychotherapy. ${ }^{+}$In the next issue he will write on practical applications of the internet for psychotherapy itself, for training and for supervision (Tantam, $2006 b, c)$.

In the preceding article (Tantam, 2006a, this issue), I considered the history of the World Wide Web and introduced some definitions of key terms. Readers who are unfamiliar with these should read that article before going on, or have an internet-savvy online encyclopaedia such as Wikipedia open.

I argued in my previous article that the internet in general, and the World Wide Web in particular, provides many opportunities to psychotherapy and counselling, but each opportunity carries with it an associated risk. I mentioned three such opportunities: information, interactivity and openness. Here I shall deal with the risks associated with each of these, and also with a fourth risk which is particular to the internet: disembodied presence.

\section{Information}

\section{Opportunities for psychotherapists and their clients}

Like other professionals, psychotherapists rely increasingly on new technologies to provide information (Wyatt \& Sullivan, 2005). The technology has evolved to make video, still pictures, graphics and audio almost as easy to capture, edit

'For Digby Tantam's first article in this short series see pp. 359-367, this issue. and distribute as text. It is now possible not only to read how psychotherapy is done, or how it was done, but to see and hear it too. Recent developments in the field have resulted in the replacement of analogue by digital encoding, by the development of standards for file compression leading to file formats that can be read by many machines and many programs, and by the convergence of telephones, televisions, cameras, computers and new devices such as personal digital assistants (PDAs), hand-held computers, MP3 players such as the iPod (players that can recognise the MP3 compression standard for digital audio files used by peer-to-peer file-sharing programs), and mobile phones that nowadays incorporate many of these digital devices within themselves.

Internet-connected personal computers and handhelds have many characteristics that make them a superior source of information to other current media. The World Wide Web is enormous and searchable. The information can be provided at your desk (or 'other point of use') when it is needed. The semantic structure of the Web means that you can use hyperlinks to 'drill down' (focus) on a particular concept or patient's problem, without having to sift so much related but ultimately irrelevant information.

Documents can be distributed or published on the internet instead of or in addition to being printed. The National Institute for Health and Clinical Excellence (NICE) makes all of its guidelines available over the internet, including recent guidelines that refer to counselling or psychotherapy (including those on anxiety, schizophrenia and self-harm). The National Library for Health (http://www.library.

Digby Tantam is Clinical Professor of Psychotherapy at the University of Sheffield (Centre for the Study of Conflict and Reconciliation, University of Sheffield School of Health and Related Research, 30 Regent Street, Sheffield S6 6GJ, UK. Email: d.tantam@sheffield.ac.uk). He is Co-Director of the University's Centre for the Study of Conflict and Reconciliation, Director of the Section of Mental Health within the School of Health and Related Research, and Deputy Director of Teaching for the School. He is also an honorary consultant psychotherapist and psychiatrist in Sheffield Care Trust. His current research interests include the evaluation of internet-based learning and teaching. 
nhs.uk), which is run by the National Health Service (NHS), contains links to NICE and many other information providers, for example the Cochrane Library, which includes studies of psychotherapy that meet Cochrane criteria. This groundswell of information has supported the evidence-based medicine approach that informed the Department of Health's strategy paper on psychotherapy (Parry, 1996).

The ICD-10, the British National Formulary (BNF) and even some textbooks are also available over the internet and in PDA-readable format.

'Expert systems' enable users to specify the kind of information that they want and allow programs to find and present selected information accordingly. For example, clinical decision-making support systems such as Isabel (http://www.isabelhealthcare.com) provide information about differential diagnosis in response to a list of symptoms and signs, suggest follow-up investigations and indicate possible management. They have not so far been extended to psychiatry or psychotherapy, but no doubt will be in the future.

Psychotherapists are just beginning to use the potential of the Web to disseminate information about therapy and therapeutic matters. A spin-off of this is that some web designers now advertise themselves specifically to therapists, and there are specialist hosts, too.

Clients and patients also have access to more and more information. The Library of Congress, as well as providing the Medline service, publishes information pages for health consumers on Medline Plus (http://www.nlm.nih.gov/medlineplus). NHS Direct's web pages (http://www.nhsdirect.nhs. uk) contain information about psychotherapy and counselling. Many other, less official, pages also exist.

The downside of all this information is that the professional is expected to use it, all of it, in making a decision. This means finding the information and correctly judging whether or not it is right.

\section{Information overload}

A new generation of librarians has turned into information scientists and developed a new science of health informatics, largely to deal with the problem of how information can be selected and presented to the user in a timely and relevant way. One approach has been to develop 'virtual libraries' such as the WWW Virtual Library (http://vlib.org). Within the latter, the Psychology World Wide Web Virtual Library (http://www.dialogical.net/psychology/ index.html) includes a site on stress management but nothing on psychotherapy or counselling.
Many of the links on this site are broken, a common problem for web-based services since hosting a site costs money, and even wonderful web pages like the University of Sheffield's own Online Dictionary of Mental Health (http://www.human-nature.com/ odmh/index.html), which was in the top $5 \%$ of sites searched by Lycos (a popular search engine of yesteryear), have to be maintained or deleted.

The best virtual libraries are those that have core funding, which ensures that they are maintained and remain current. The NHS's National Library for Health is a UK example. It is password protected via the widely used Athens password protection system (unlike the open-access National electronic Library for Health (NeLH; http://www.nelh.nhs. uk), which it is gradually replacing), but all NHS staff are eligible to register for an Athens password (at http://www.athens.nhs.uk) and can therefore enter the site.

The corresponding open-access library to replace NeLH is maintained by NHS Direct Online (http:// www.nhsdirect.nhs.uk) and is oriented more to potential users of health services. It is available via digital television as well as over the Web. Other world governments provide a similar service (e.g. the US National Institutes of Health at http://health. nih.gov; Health Canada at http://www.hc-sc.gc. ca; and HealthInsite in Australia (http://www. healthinsite.gov.au).

Electronic libraries do help to collate information and serve it up in a useful way, but they also contribute to the downpour of information available. Information overload is likely to be a persistent problem that will not soon go away.

\section{Misinformation and disinformation}

One of the biggest worries about the internet was that it would promulgate, either intentionally or not, false information (a worry that could equally be applied to books, newspapers, radio and television). Although there are official websites nowadays, such as NHS Direct Online and Medline Plus, which provide portals to vetted information, the majority of websites carrying information about mental health are not peer reviewed. Many exist to further the private or commercial interests of their webmasters. The potential risks of this depend, of course, on the users. If they believe all that they read and choose to look at only one or a few sites, there is a risk that they will be misinformed or, perhaps worse, taken in by deliberate disinformation. Even if users do not believe all that they read, if they do not consider some information as intrinsically more reliable than other there is again the risk of misinformation: the wheat gets lost in the chaff. 
Two studies of web pages related to depression show that these might be significant problems. One concluded that people with depression might be put at risk through the advice offered by these websites (Ernst \& Schmidt, 2004). The same study found that most of these sites suggested complementary treatments for depression and only two suggested psychotherapy. Similar conclusions were reached in an earlier, pre-Google study by Lissman \& Boehnlein (2001).

Causes of misinformation can be unintentional, for example lack of currency as information becomes out of date, and intentional, as in bias. Bias may arise from prejudice or from commercial interest. A useful document produced by one of the libraries at the University of North Carolina (http://bullpup. lib.unca.edu/library/lr/evalweb.html) suggests that contextual information can be used to evaluate websites, just as it can in our evaluation of the more familiar media of books or newspapers. One of the contextual clues mentioned is the URL. If it ends in .edu or, in the UK, .ac.uk, it is an academic site and might be more unbiased than a site with a URLending in .me or .com, which imply no particular affiliation. Sites ending in .co.uk or .biz are commercial sites. Many sites contain advertisements, and the content of these can be a clue to the reliability of the site. Contextual information obtainable in the site content includes clues to the date on which it was created or last modified (this might also be shown explicitly), and whether or not the two sides of a controversial issue are presented.

Thus, information is a boon and a curse. A boon if the right information is available at the right time, a curse if it is lost in a mass of irrelevant information or if the information is misleading or incorrect. In practice, most people are adept at using contextual cues to sort out false information from true even if they are unfamiliar with the subject matter.

\section{Interactivity}

The plethora of emails that most professionals receive is one example of the pressures for communication created by the internet. The impact of this is only starting to be felt. It seems inevitable that our clients will expect more and more communication from us before they even see us, and will no doubt expect us to answer more and more of their questions posed by email, in addition to those they put to us in person.

\section{Opportunities}

Communication with clients before they are seen helps to ensure that the practical arrangements for appointments are carefully worked out, which will reduce missed appointments and drop out from therapy. Communication after visits means that advice can be clarified, where necessary, and is also a valuable form of feedback about what the clients heard their therapist to say or not say.

Communication by clients may help them to formulate their problems clearly and may even be of immediate value (I am grateful to an anonymous reviewer for this suggestion, in that writing about psychological difficulties has been shown to reduce distress in adolescents (Soliday et al, 2004) and may in itself be a therapeutic intervention).

\section{Risks}

Interactivity encourages spontaneity, but it also predisposes to quick, and sometimes unreflective, responses. Sending copies of emails to other people is also tempting, but when these are managers or senior colleagues, the effect may be to heighten tension. Multiple emails can also result in a kind of anonymity which is irritating, and they sometimes lead to inadvertent breaches of confidentiality, since what it is appropriate to reveal to one person on a list may not be appropriately revealed to another.

In the longer run, psychotherapeutic practice will have to be considered as extending beyond the consulting room and the session. New principles will need to be addressed to maintain appropriate boundaries. It will have implications for staffing and costs. Psychotherapists will also need to learn new techniques, not dissimilar to the 'dynamic administration' techniques described by group analytic therapists. Two techniques that my own research has identified are (a) always acknowledge communications and (b) do not respond to challenge with negativity. These apply just as much to virtual communications as to messages to the group, and for the same reasons. Both situations pose threats to identity. It is easy for a person to become 'invisible' in both situations, and also for them to be relegated to a sub-group, unless the therapist/teacher keeps that person in mind and reaches out to them when they make contact.

\section{Openness}

Very little of the information on the internet can be restricted to professionals. Indeed, many of those who are best disposed to the internet champion this openness and would want no censoring and no commercial restriction of any sort. Increasingly, patients are finding out information about therapists before contacting them, from personal or employers' websites, or from the websites of professional 
organisations who are more and more, as predicted in an earlier article on the internet (Tantam, 2001), publishing their registers of members and accredited therapists.

The internet is accessible to anyone with the appropriate hard- and software and is, at least to the average user, often anonymous. Laws controlling libel, incitement to hatred, copyright and depravity extend to the internet, but are difficult to apply, not least because many websites are created in jurisdictions other than the ones in which their users reside. The Chinese government has been largely successful in censoring the sites that its citizens can access, but few other governments have had the time or inclination to do this. One unexpected side-effect of this is that libertarian groups have constructed methods for truly anonymous surfing (going from site to site on the internet), which can now be used to ensure untraceable access to criminal or pornographic sites.

With more and more professional information available on the internet for free, another kind of problem of openness arises. Clients and patients can read our journals and our books, check the web pages of our societies, even look at our personal pages, if we put them on the internet. I write 'our' because before this professionals often assumed that their own particular language, meeting places and publications were reserved to them alone. I remember the shock that psychotherapists felt with the introduction of the Freedom of Information Act 2000, and the knowledge that patients might ask to read case-notes (not that they very often do). Where were psychotherapists to write their private thoughts about their patients, thoughts that seemed essential to the process of clinical reflection?

The openness of the internet allows clients to see much of the information that their therapists see and to interpret it for themselves. They can also participate in professional disagreements and read psychotherapy's critics. Can this be good? Moreover, there are plenty of people who are not committed to the professional ethics of psychotherapy, or who profoundly reject its values, who are able to publish on the internet themselves about all of the most challenging issues: medication or its lack, psychotherapy's difficulties in establishing an evidence base, the margins of psychotherapy and other, less public-minded, influencing methods.

Already professional practice is having to become more open across the board, and the internet is likely to accelerate this. There will be both advantages and disadvantages, which are only now beginning to emerge. Some psychotherapists feel, for example, that the effect will be to create a kind of defensive practice in which the threat of litigation will suppress the professional's freedom of expression.

\section{Disembodied presence}

None of the risks of the internet that I have so far considered is unknown. They all apply to other broadcast media to which we have become accustomed. The internet simply amplifies them by increasing the intrusiveness of the broadcast. However, digital media, the internet especially, do pose one new challenge.

\section{Virtual person, or nobody at all}

Letters are delivered by a postman or -woman, who may know the person to whom they are addressed and certainly knows where they live. We can easily send an anonymous letter, but it is much harder to have an anonymous correspondence by letter. Anonymity is the norm with electronic communication. The name that people use on, say, MSN Messenger may express an aspiration or an attitude, but it does need to express a recognisable identity (Gerhard et $a l, 2004)$. The machine finds us from our IP address not from the return information. We can therefore freely choose the apparent identity that other parties will see. Interestingly, this is one way that electronic communication is closer to psychotherapy than to many other human encounters. Psychotherapists, too, may rely completely on the information given them by their clients, and certainly on their clients' perspective on their lives. There is always the danger that psychotherapists may be completely deceived by an unscrupulous or scheming client.

For some reason, this anonymity in person rarely troubles psychotherapists, but the anonymity of the internet or even telephone contact with someone one has never met is troubling. A possible explanation of this is in the importance of embodiment. Disembodied interactions allow for much greater deception than embodied transactions, or so it seems.

Two embodied actors who meet face to face cannot help but disclose something of themselves. They are, inescapably, committed to personal engagement with each other (although there are many cultural methods for minimising this disclosure by disguising oneself with make-up, clothing, bodily rearrangement and so on). The possibility of deception is reduced. Compare this with electronic meetings, where a person may falsely declare their gender, their age, their ethnicity, their sexual orientation, indeed almost any key aspect of their identity.

Many psychotherapists make it a requirement to have at least met their clients face to face before working with them electronically. However, others consider that a sufficiently authentic encounter can be created even without face-to-face meetings by paying particularly close attention to the details of the interaction. 


\section{Presence}

Being with a person means experiencing the presence of another person. It is difficult to analyse this. It almost certainly involves being bathed in the nonverbal communicative traffic that passes between people. This is not suspended by computer mediation. 'Smilies' (such as :-/), conventions (such as lol, which stands for 'laugh out loud') and the increased use of information about environment or mood have all been adopted by regular users of internet chat rooms and mobile phone texting to reintroduce information that would normally be 'present' without any communicative effort. However, computers on their own, without human users also being present, can only begin to mimic this (Schuemie et al, 2001).

But nonverbal communication does not seem essential. Responsiveness may be enough. Even the 1960s generation of chatterbots such as ELIZA (described in detail in the next issue: Tantam, 2006b) had users who formed emotional relationships with the computer (users do not of course differentiate between the device and the program) (Lindgaard, 2004). Our capacity to see personhood in objects in our environment and to imbue them with intentionality and emotional responsiveness towards us is considerable, as is evident in attributions of personhood to trees, the sun's disk, cars and so on. This process is often misnamed 'projection' by analogy with the metaphorical description of our capacity to attribute our own motives to others, first described by Melanie Klein.

Conversations with people over a computer often create the sense that the other person is present, and may be the basis of people falling in love, making alliances or being persuaded against their better judgement to do unlikely things. However, there is a recognition that the presence may not be what it seems. As has become notorious, an adolescent girl in a chat room may in reality be a middle-aged man. Some believe that electronic communication offers the potential of a 'virtual' identity and a 'real' identity (others would say that we have the possibility of several identities, so which is real?). This capacity of the internet is sometimes called 'virtuality'.

\section{What's the problem?}

It is not really anonymity, because psychotherapists often know little about their clients other than what the clients tell them, without corroboration. My own view is that the problem is disembodiment. Meeting someone in the flesh is special because we perceive their bodies. But a phone call is still, partly, embodied. We can hear a person breathing, for example. Even a typewritten letter has a degree of embodiment: some letters are bolder than others because the typist has pressed harder on that key. Word-processed letters are not like this, nor are text messages. They give no inadvertent clues of the body of the person who writes them.

\section{Embodiment}

'The body has been typically assumed, by scholarly and popular thought alike, to be a fixed, material entity subject to the empirical rules of biological science, and characterized by unchangeable inner necessities' (Csordas, 1994). Many of us would also agree that embodiment is one of the defining characteristics of being a person (Martin, 2003). However, the word 'embodiment' has become popular precisely because it is possible to think of being a person, but not located in a body, or being a person whose body or bodily awareness is changed, for example by violence, by designer surgery or by self-mutilation.

Merleau-Ponty (1962) introduced the distinction between an objective and a phenomenal body. The two normally coincide. Our objective body, the physiological machine, is what is contained in our skin and what others see when we are physically present. Our phenomenal body is what we experience as a body within the limits of our perception and our motor control. When we drive a car, the limit of our phenomenal body may be the bodywork of the car. We may wince when it is damaged, or feel that not just the car we are driving but we ourselves have the capacity to accelerate quickly. It is likely that a passenger will have only a limited or no phenomenal extension of their body in this way. So the phenomenal body is a creation of activity of some kind. Being on the internet, clicking on the mouse or typing on the keyboard are activities that can create a phenomenal experience that we related to. We may experience ourselves as moving through or living in an environment or space - cyberspace - in which we are present as we are normally present in our physical environment. We can be present in cyberspace without our objective bodies being there at all, and this state of 'disembodied presence' creates some of the particular challenges posed by the internet (Quick \& Dautenhahn, 1999).

When psychotherapy is (rightly) considered to be a highly personal activity, it is generally assumed that it must involve meeting people in the flesh. Machine-mediated psychotherapy flies in the face of that, and for some people is enough to make disembodied psychotherapy an oxymoron. These psychotherapists would argue that when a client is present in their own body, they cannot conceal 
cues to their identity that psychotherapists consider essential to an understanding of that person's difficulties. This includes the obvious cues to gender and age, and also information about social status (in a person's dress) and marital status (rings), or leakage about deception, anxiety or depression.

Anonymity in internet supervision or therapy is profound. A person can masquerade as someone completely different if they choose. In a post-modern world this might be taken to be quite as it should be. After all, why shouldn't a middle-aged man present himself as a teenage girl if that is how he feels himself to be? In practice, virtual psychotherapy only works when both client and therapist present themselves as they really are and not as they virtually could be.

\section{The look}

Many people have commented on the ways that people conduct themselves on the internet. One common factor is that people behave as if they were in private and alone even when their behaviour can be publicly scrutinised or they are interacting with others. One reason for this may be the absence of a physical awareness of the presence of others, an awareness that Sartre characterised as 'the look' - feeling the scrutiny of others and being influenced by the awareness of how what one does looks to them.

The absence of the look may enable a person to talk about their problems to another person on the internet although they would feel too ashamed to talk in the flesh.

Arguably the most crucial element of embodied presence is the gaze or look of the other or others who are present. Computers may be linked to webcams but these have no gaze, only a visual field. Gaze indicates attention, and its absence makes internet teaching more taxing. The look also induces self-consciousness and therefore the possibility of shame (Morris, 2003). The absence of shame can be advantageous, as we shall see later (Tantam, 2006b), in the computerised administration of tests. It may also allow people to interact virtually who would be prohibited by shame or social anxiety from interacting in the flesh. Conditions that may lead to an unwillingness to bear scrutiny include eating disorders, repeated self-wounding and bodily shame associated with sexual abuse.

The absence of a normal level of shame may be one factor that leads to the disinhibition (Suler, 2004) that is characteristic of internet users. This is apparent in their willingness to post aggressive ('flame'), offensive or sexually explicit messages in chat rooms, discussion groups and elsewhere on the internet. It may also be a factor in the readiness of internet users to gamble or visit pornographic sites.

\section{The internet and perversity}

Gambling and pornography are the main cash earners on the internet. Both can lead to addictions. Addiction to erotic or 'adult' material on the internet may involve a range of sexual activities and may lead to meeting partners or potential partners in reality. There is a growing literature on the impact of this problem on individuals and on couples, and on its treatment (Barak, 2006). Internet-based gambling addiction seems to have fewer special features to distinguish it from other gambling addictions.

\section{Dissociation}

People's surfing habits cannot just be explained by their shamelessness. There is, as I have already noted, what people often call an addictive quality to many aspects of computer use. The same is true, and probably for the same reasons, of computer, arcade and console games. People become entranced on the internet and lose their sense of the passage of time. Internet users regulate themselves and their behaviour less effectively (LaRose et al, 2001). Users do seem to experience these environments as alternative worlds. This too seems linked to disembodiment, as if a person could take themselves out of their body and transfer themselves into cyberspace. In the case of some multi-user games, a user may be able to create a character with a life of his or her own, interacting with other virtual characters in many different situations within the virtual environment. Computer and games use are conducive to splitting or dissociation (te Wildt, 2004; te Wildt et al, 2006) and this, in turn, may contribute to the disinhibition that characterises usage of the internet, chat rooms and texting (Griffiths et al, 2004).

\section{Where will it all end?}

It is hard to say where this will end. One can say, though, that as much as new technologies create problems, so they also offer the potential for new solutions. It is to these solutions, these electronic approaches to psychotherapy, that I will turn in my next two articles (Tantam, 2006b,c). I begin with the most contentious approach: replacing the psychotherapist, tester, trainer or supervisor with a machine (Tantam, 2006b).

\section{Declaration of interest}

None. 


\section{References}

Barak, A. (2006) Net Behaviour and Usage (References Related to the Internet $\mathcal{E}$ Psychology). http://construct.haifa.ac.il/\%7Eazy/ refbehav.htm

Csordas, T. J. (1994) Body. In The Social Science Encyclopedia (eds A. Kuper \& J. Kuper), pp. 55-56. New York: Routledge.

Ernst, E. \& Schmidt, K. (2004) 'Alternative' cures for depression - how safe are websites? Psychiatry Research, 129, 297-301.

Gerhard, M., Moore, D. \& Hobbs, D. (2004) Embodiment and copresence in collaborative interfaces. International Journal of Human-Computer Studies, 61, 453-480.

Griffiths, K. M., Christensen, H., Jorm, A. F., et al (2004) Effect of web-based depression literacy and cognitive-behavioural therapy interventions on stigmatising attitudes to depression. Randomised controlled trial. British Journal of Psychiatry, 185, 342-349.

LaRose, R., Mastro, D. \& Eastin, M. S. (2001) Understanding internet usage. A social-cognitive approach to uses and gratifications. Social Science Computer Review, 19, 395-413.

Lindgaard, G. (2004) Adventurers versus nit-pickers on affective computing. Interacting with Computers, 16, 723-728.

Lissman, T. L. \& Boehnlein, J. K. (2001) A critical review of internet information about depression. Psychiatric Services, 52, 1046-1050.

Martin, J. (2003) Emergent persons. New Ideas in Psychology, 21, 85-99.

Merleau-Ponty, M. (1962) Phenomenology of Perception. London: Routledge and Kegan Paul.

Morris, K. (2003) The phenomenology of body dysmorphic disorder: a Sartrean analysis. In Nature and Narrative (eds B. Fulford, K. Morris, J. Sadler, et al), Oxford: Oxford University Press.

Parry, G. (1996) NHS Psychotherapy Services in England: Review of Strategic Policy. London: NHS Executive.

Quick, T., Dautenhahn, K. (1999) Making Embodiment Measurable. Workshop contribution to Embodied Mind/Artificial Life. Fachtagung der Gesellschaft für Kognitionswissenschaft, 28 September to 1 Oktober 1999, Bielefeld (KogWis99). Available at http://www.cs.ucl.ac.uk/staff/t.quick/kogwis/webtext. html

Schuemie, M. J., van der Stratten, P., Krijn, M., et al (2001) Research on presence in virtual reality: a survey. CyberPsychology $\mathcal{E}$ Behavior, 4, 183-201.

Soliday, E., Garofalo, J. P. \& Rogers, D. (2004) Expressive writing intervention for adolescents' somatic symptoms and mood. Journal of Clinical Child and Adolescent Psychology, 33, 792801.

Suler, J. (2004) The online disinhibition effect. CyberPsychology $\mathcal{E}$ Behavior, 7, 321-326.

Tantam, D. (2001) A guide to the internet for psychotherapists. Psychiatric Bulletin, 25, 29-30.

Tantam, D. (2006a) Computers, the internet and the World Wide Web: an introduction for the e-therapist. Advances in Psychiatric Treatment, 12, 359-367.

Tantam, D. (2006b) The machine as therapist: impersonal communication with a machine. Advances in Psychiatric Treatment, 12, in press.

Tantam, D. (2006c) The machine as intermediary: communication with a therapist via a machine. Advances in Psychiatric Treatment, 12 , in press.

te Wildt, B. T. (2004) Psychische Wirkungen der neuen digitalen Medien. Fortschritte Neurologie und Psychiatrie, 72, 574-585.

te Wildt, B. T., Kowalewski, E., Meibeyer, F., et al (2006) Identität und Dissoziation im Cyberspace Kasuistik einer dissoziativen Identitätsstörung im Zusammenhang mit einem InternetRollenspiel. Der Nervenarzt, 77, 81-84

World Health Organization (1992) The International Statistical Classification of Diseases and Related Health Problems, Tenth Revision (ICD-10). Geneva: WHO

Wyatt, J. C. \& Sullivan, F. (2005) What is health information? BMJ, 331, 566-568.

\section{MCQs}

1 The phenomenal body is:

a a concept of the philosopher Merleau-Ponty

b always larger than the objective body

c always smaller than the objective body

$\mathrm{d}$ a clue to the experience of bodiless presence on the internet

e fixed by an individual's identity.

\section{Disinhibition and the use of the internet:}

a may be increased because no one is looking at what the user is doing

b there is less risk of feeling shame

c may lead to aggression

d should make therapists avoid using the internet

e can help overcome social avoidance.

3 Identity:

a one person can only have one identity

b dissociative disorder can be increased by the adoption of alternative identities on the net

c having several different identities is always pathological

d having several different identities is always immoral

e adopting another identity on the net can be a way of duping or exploiting others.

4 Emails from clients:

a can be a valuable extension to therapy

b do not cost the therapist anything

c cannot be ignored

d present new challenges to confidentiality

e should normally be considered a breach of the therapy's boundaries.

5 Virtual libraries are:

a systematic

b normally searchable

c normally up to date

d mainly commercially sponsored

e open to all.

\section{MCQ answers}

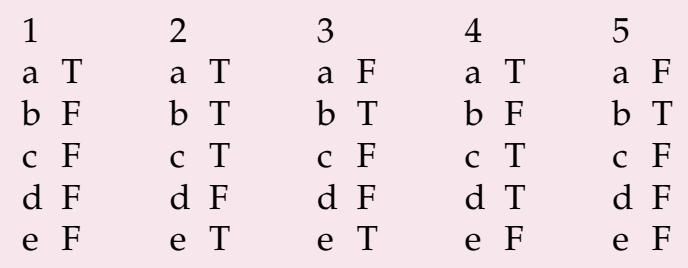

